\title{
The Significance of Ethics in Educational Institutions: A Literature Review
}

\author{
Ronnie L. Torres OMI
}

\begin{abstract}
We have witnessed and experienced the deterioration of ethics and values in schools in all levels administrations, teachers, students and non-teaching personnel. Moreover, the school has become more diverse in terms of race, culture and traditions, political views, religions and the like. It is likely that those in the educational system experience ethical dilemmas that if not given immediate attention may lead to serious complications. The author tries to delveinto the ethical issues the educational institutions experience, the dilemmas they face, and offer recommendations to alleviate the problems. This paper emphasizes the necessity of developing curative and educative programs that will help members of the educational system to manage, teach and produce ethical individuals. This paper also offers opportunities to readers and future researchers to deeply investigate into the various identified ethical issues,most especially in developing comprehensive programs that may help school administrators to run educational institutions based on ethical standards.
\end{abstract}

Index Terms - ethics, ethics in education, education and ethics.

\section{INTRODUCTION}

This term paper tries to discuss the importance of ethical and moral values that all levels within the educational institution should possess. Specifically, this paper will discuss the followingcomponents: ethics and diversity, ethics and students, ethics and teachers, and ethics and administrators. The author believes that the above-mentioned components are the most important mechanisms of the educational institution although there are other elements that may encompass the system.

Nowadays, there are countless manifestations of attitudes that show the weakening if not vanishing of ethical and moral values in school - from students disrespecting teachers, lying and cheating, bullying and discriminating fellow students, destroying school properties, bashing teachers in social media displaying public display of affection, disobeying school rules and regulations; to teachers backbiting each other, deliberately defying contracts, disobeying orders, corrupting money, negligent in teaching, involved in illicit relationships, showing hatred towards students and colleagues; to members of administration demonstrating professional jealousy, playing favoritism to whom they know, self-serving policymaking, exploitation of designation,blatant display of racism and the like.

The school is the arena where teachers and administrators are

Ronnie L. Torres OMI, Deputy Director of Saint Nicholas School in Phitsanulok, North of Thailand motivated and empowered to practice their profession with dignity by delivering quality service to their clientelethrough effective management and quality classroom teaching. It is not enough that administrators come to the meeting every week to report to the director what their accomplishments for the week are, what their complaints are, or be present for attendance's sake; or for teachers to come to school for bread and butter, to finish the syllabi for the term, and to teach so that students can pass the national aptitude test. The school needs administrators and teachers who ensure that the school and students aremanaged to optimize performance and responsibility, ensure that ethics, values and goals are reflected and applied in the school system, and establish meaningful relationshipsamong all members of the system toexpress everyone's commitment as they lead their wards (Karri, et.al, 2005).

All these can only be achieved if all the members of the school system possess not only the desired skills but also the much-needed ethical values. Without these, the essence of the school is defeated. But, how can this glorious idea be materialized?

\section{REVIEW OF LITERATURE AND STUDIES}

\section{A. Ethics and Diversity}

The world is becoming smaller and smaller, schools come to be more technologically advanced, andeducational institutions are more diverse in terms of color, religious beliefs, nationalities, language, political views, culture and tradition among others.Diversity paints a beautiful picture of a dynamic educational institution, but at the same time poses serious problems, struggles and misapprehensions. In order to strike the balance, ethical behaviors are needed.

Ethics plays a very important role in a diverse society as it deals with moral aspects of human relationships and it cannot be separated from our existence. Ethics presents the relationship of the human to him/herself, to others, and to the society as a whole (Josefova,2016). On a bigger sphere, a harmonious society operates on the ideal concept of multiculturalism that is based on a cooperation of different races, cultures, religions, ethnic groups, and ethical behaviors (Josefova, 2016). However, multiculturalism also brings problems not only on economic, political, social and cultural but also ethical as there are varied attitudes of people, value systems, traditions and habits that each person exhibit in their families, at work, in education, in communication and in their public endeavors (Josefova, 2016).

Thus, in the midst of this rapid change in the school 
environment, educational institutions must have knowledgeable and well prepared administrators and teachers, and they must establish an adaptive institutional climate that is responsive to changing circumstances while they declare their commitment to a set of principles and ethical values that reflect the ideals of fairness, equity and harmony among all members of the educational institution (Harvey, 2011).

Considering that education plays a very important role in shaping the society, educational institutions must be very serious in facing this rapid change in the educational milieu. Ethical and moral standards must be imparted to all members of the educational institution regardless of the above-stated variances so that they will appreciate and celebrate diversity without taking away from them their identity.

Aside from devising effective professional development and academic curricula that would address the concerns of integrating everyone into the institution, the school should also integrate common ethical standards and moral values that will address variety of differences among students, teachers and administrators. Schools should require administrators and teachers to device effective ethical professional development courses and undertake formation tracks on humanities on a periodic basis. Student should be molded to appreciate common good, celebrate diversity, advocate dialogue, uphold harmonious diverse society, employ accountability and responsibility, and live ethically and morally.

Without common ethical standards, educational institutions might experience different complicated problems that maypotentially result to conflict and disunity, formation of sub communities and groups, insubordination, or worse, the disintegration of the whole school system (Berger, 1986).

\section{B. Ethics and Students}

The school is the best training ground for students to be God-fearing, law-abiding and peace-loving citizens. Schools play a very important role in shaping their minds and hearts. Schools should not only focus on producing individuals who are academically excellent, but also possess ethical and moral values and soft skills, else, the society will be filled with intellectual giants but ethically and morally dwarves.

Ethics is vital in the personal and the future professional lives of students. The corporate world nowadays look for employees who possess ethical behaviors and not only skills and intelligence. While in school, it is important for students to be taught ethical and moral aptitudes (AMA Wire, 2018). It is not enough for students to greet their teachers when they see them, follow the yellow line when treading the corridors, pay when they destroy something, perform community service when they did something wrong, or adopting a carrot and stick policy in the classroom.

According to AMA Wire (2018), the following are five basic principles of ethics that are common to all faiths and cultures and should be taught to every studentat home and in school:

1. Do no harm.

2. Make things better.

3. Respect others.

4. Be fair.

5. Be loving.
As to how these ethical elements be cascaded to students, AMA Wire (2018) claimed that there is not one single approach to teaching ethics, but it suggests that students must understand ethical standards and how they meet them in practice while they are still in school.Weybretch (2016) however,enumerated the following tips on how ethics should be taught to students:

1. Make room for ethics;

2. Focus on examples of situations;

3. Focus on real-life experiences;

4. Go beyond what is right and wrong and into the reasons and impacts;

5. Practice;

6. Challenge students;

7. Give students the chance to ask questions;

8. Expose students to variety of experiences;

9. Ethics is not only found in the classroom;

10. Ethics is not just about students.

\section{Ethics and Teachers}

Indeed, it is true that ethics is not just about students, it is also about teachers whom students look up as their role models and second parents. Teachers plays a very important role in education. They are regarded as the source and power of the school and look upon as the backbone of the educational system (Puhan, Lakshmipriyam, and Santosh, 2014). They create big impact on students' learning outweighing any educational program or policy. They are in the school not only to transmit the acquired knowledge through studies and continuous professional development, but to form students and youth who will become the future leaders of the country. It is said that "a school without a teacher is just like a body without a soul, a skeleton without flesh and blood, and a shadow without a substance" (Puhan, Lakshmipriyam, and Santosh, 2014)

With these lofty admirations for teachers, they are expected to be extra cautious of upholding their profession like a "china in one's hand". As teachers, they are entrusted with a position of responsibility to maintain and merit the already established respect, it is therefore essential for teachers to be aware of the significance of their profession at all times and conduct themselves in an ethical manner.

Currently, teachers have confronted multiple ethical dilemmas. According to (Balakrishna, Sarin, 2017), the issues that have contributed to the erosion of ethics among teachersare as follows:

1. Recruitment and admission of teachers and awarding of degrees to teachers are purely driven by monetary considerations;

2. Rising levels of plagiarism, especially in relation to academic and scientific writings that has been observed of late in higher educational institutions; this was also affirmed by Proshakain (2013) his study entitled Encouraging Students' Ethical Behavior;

3. Poor professional standards of teachers with respect to attendance, quality of delivery of instructions and emotional involvement and emotional interaction within the classrooms;

4. In the epitome and discharge of professional 
responsibilities, the humane approach and values that should be the fundamental feature of this discipline has now metamorphosed into a quality that is under threat or extinction; and

5. In the science and technology sector, where innovations guided by a sense of what is just for the society and environment at large, is being rapidly replayed by ones with pure economic needs.

Added to that, Puhan et al. (2014) mentioned corruption as the major cause in the ethical deterioration of the educational system. He quipped that nowadays, corruption has spread its roots into the educational system. He further defined that corruption in education is defined as

"...the systematic use of public office for private benefit whose impact is significant on the availability and quality of educational goods and services which may include bribes and illegal fees for admission and examination; academic fraud; withholding teachers' salaries, preferential promotion and placement, charging students for tutoring session to cover the curriculum needed to pass the mandatory examinations which should have been taught in the classroom, and infrastructural work."

Other factors as quoted by Puhan, et.al(2014) include privatizations of educational institutes, political interferences, care in teacher-student relationship, unfair assessment, absenteeism, and missed ethical education in current teacher training curriculum and so on. All these, result to a poor quality of education and a lack of ethics among teachers which are cascaded to the students.

To give remedy to these pressing dilemmas, Balakrishna and Sarin (2017)on one hand, suggested to strictly evaluate teachers at their respective levels and be oriented to be civilized individuals who can make sound judgements related to self and society; however, they claimed that, "as we value teachers to be role models and inculcators of values, which they themselves should live and lead a value-based life," they failed to propose a framework for the integration of the above mentioned into the educational system. On the other hand, Puhan, et.al. (2014), offered recommendations to strengthen ethical values among teachers, philosophical thinking, study, research and moral development in educational system by providing programs and trainings, support groups, lessening teacher preparation and workloads, continuing professional education, and teacher pedagogical reorientation.

\section{Ethics and Administrators}

If teachers are considered the backbone of the educational system, it is safe to consider that administrators are the lifeblood of the school because it is through them and their effective administration and governance that the success of the school and the notch of reaching the school's vision and mission are set.

In their everyday decision-making, administrators shape their decisions carefully because they affect their teachers and students' lives, making leadership and administrative decisions an ethical issue (Vogel, 2012). And since, educational leadership has become more complicated as schools become more varied and schools have been entrusted with numerous tasks, institutions have developed code of ethics for administrators to make more specific, practical, idealistic, detailed and applicable ethical codes that would specifically apply to their situations (Kocaba, Karakose 2009).

According to Kocaba and Karakose (2009). the concept of governance incorporates four fundamental issues which are enfleshed by school administrators, cooperated by every member of the educational institution, are the following:

1. How an organization is managed to optimize performance and accountability;

2. how values and goals are reflected by the systems and structures that are created;

3. How leaders establish relationships that engender the commitment of those who work with and for them; and

4. how the application of leadership is formally applied in the conduct of organizational business.

Despite the existence of these principles, Kocabas and Karakose (2009) argued that a lot of administrators face dilemmas, not in choosing what is right from wrong but from two rights, in their decision making. Further, he cited that administrators face ethical issues mostly about faculty, students, financial matters, and relations with the public.But Gardiner and Tenuto (2015) underscored that ethical dilemmas faced by administrators are much deeper than the above issues. The following are ethical issues in institutions as cited in the study of Gardiner and Tenuto (2015):

1. Cultural differences and situations of conflict concerning race, ethnicity, and/or other differences;

2. The need to process and adequately address the resulting behaviors connected with conflicts stemming from these differences; and

3. Decisions made in immediate situations without the benefit of reflection or a model designed to process ethical decision-making.

Other than external issues, Kocabas underscored that a lot of administrators need professional training regarding ethical decision making and that they should be prepared to respond to the challenges of the complexities of contemporary school leadership through professional development programs (Kocabas and Karakose, 2009).

It is a must that educational institutions should employ qualified school administrators who are equipped not only professionally but also ethically because they hold responsibilities of making decisions that may affect not only their own professional and personal lives, but the lives of their teachers and students, the educational system in where they are in, and the society as a whole.

\section{CONCLUSION AND RECOMMENDATIONS}

We witness countless signs of the weakening if not vanishing of ethical and moral values in educational institutions - from students, teachers and administrators. Recognizing that schools become more diverse in many respects, every member of the educational institution must strike the balance. Ethical behaviors are needed in order to maintain fairness, equity and harmony among members of the educational institution. In order achieve this, educational institutions 
must have knowledgeable and well-prepared administrators and teachers. Aside from devising professional development programs, formation tracks, and academic curricula that would integrate everyone into the system, ethical and moral standards must be imparted to all so that they will appreciate and celebrate diversity without taking away from them their identity.

The aim of every institution is to produce students who are God-fearing, law-abiding and peace-loving citizens. Ethics is vital in the personal and the future professional lives of students. To achieve this aim, students must be taught to do good, to respect, to be fair and to love. Educational institutions should devise effective pedagogies that gives rooms for ethics and real-life experiences that let students practice ethics.

It is indeed true that ethics is not just about students, but also about teachers because teachers are regarded as the source and power of the school and look upon as the backbone of the educational system. They are in the school not only to transmit the acquired knowledge but to form students who will become the future leaders of the country, thus they have to always conduct themselves in an ethical manner. However, teachers nowadays have confronted multiple ethical dilemmas that affect the quality and ethical values of teachers. To remedy, teachers should be strictly evaluated, strengthen their ethical and professional values by providing meaningful programs and trainings, support groups, lessening teacher preparation and workloads, continuing professional education, and teacher pedagogical reorientation.

Administrators are the lifeblood of the school because it is through their effective administration and governance that the success of the school are met. Administrators should follow certain ethical standards in their decision making for their decisions affect not only their personal and professional lives, but also their teachers, students and other staff. Despite the existence of ethical principles, administratorsstill face dilemmas in their governance, not in choosing what is right from wrong but from two rights. Administrators face ethical issues mostly about faculty, students, financial matters, and relations with the public and some other deeper issues like cultural differences. Administrators must be professionally and ethically qualified. They should undergo professional trainings regarding ethical decision making and that they should be prepared to respond to the challenges of the complexities of contemporary school leadership through professional development programs.

As soon as concerned educational institutions implement above-mentioned recommendations, the outcome will surely lessen ethical problems within the educational systems. However, future researchers are encouraged to delve deeper to examine and understand deeply each of the dilemmas;and recommendations mentioned require careful attention and scrutiny to extend effective solutions to the problems and enhance the educational system.

The author believes that in an educational system governed by ethical administrators, refined by ethical teachers, the outcome of the education process will surely be ethical students who are the future workforce and leaders of the country where they belong.

\section{REFERENCES}

[1] AMA Wire. (2018). The top 10 ethical issues students should be taught. [online] Available at: https://wire.ama-assn.org/education/top-10-ethical-issues-students-sho uld-be-taught [Accessed 13 Apr. 2018].

[2] Balakrishna, P., \& Sarin S. N. (2017, September 20). Ethics and Education. Retrieved April 13, 2018, from http://tdu.edu.in/ethics-and-education/

[3] Berger, P.L. (1986). Sociology reinterpreted: An essay on method and vocation (p. 570). New York: Anchor Books.

[4] Dempster N., Berry V. (2003). Blindfolded in a Minefield: Principals' ethical decision-making.Cambridge Journal on Educ. 33(3): 457-477.

[5] Gardiner, M.E., Tenuto, P.L. (2015). Reflections of Practicing School Principals on Ethical Leadership and Decision-Making: Confronting socialInjustice. The Journal of Values-Based Leadership. 8(2) A6.

[6] Harvey, W.B. (2011). Higher education and diversity: Ethical and practical responsibility in the academy (p. 3). Kirwan Institute: Ohio State University.

[7] Josefova, A. (2016). The importance of ethics in the process of education in today's globalized society. Journal in Humanities. 4(1): 5-9.

[8] Karri R., Caldwell C., Antonacopoulou E.P., \&Naegle D.C. (2005). Building trust in business schools through ethical governance. Journal on Acadademics: Ethics. 3 (2/4): 159-182.

[9] Kocabas, I., Karakose T. (2009) Ethics in school administration. African Journal of Business Management. 3(4): 126-130.

[10] Puhan,R.M., Lakshmipriyam M., and Santosh K.B. (2014). Current Ethical issues in Teacher Education: A critical analysis on pre-service and in-service emerging teachers. American Journal of Education Research 2.12A (2014): 1-7.

[11] Prohaska, V. (2013, May). Encouraging Students' Ethical Behavior Retrieved April 13, 2018, from http://www.apa.org/ed/precollege/ptn/2013/05/ethical-behavior.aspx

[12] Vogel, L.R. (2012). Leading with hearts and minds: ethical orientations of educational leaderships of doctoral students. University of Northern Colorado, Greeley, Colorado, USA. Available at: http://3f17112qoj413y6ep2tqpwra.wpengine.netdna-cdn.com/wp-conte nt/uploads/2014/05/VEEA-Vol10-No1.pdf [Accessed 28 Mar. 2018].

[13] Weybrecht, G. (2016). How to teach students to be ethical. Available at:

http://www.aacsb.edu/blog/2016/december/how-to-teach-students-to-b e-ethical [Accessed 28 Mar. 2018].

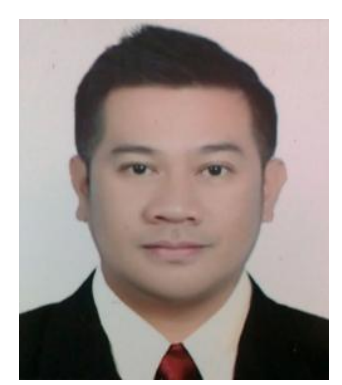

Ronnie Torres, OMI is currently the Deputy Director of Saint Nicholas School in Phitsanulok, North of Thailand. He is a $\mathrm{PhD}$ Candidate and a graduate of MA in Pastoral Ministry; MA in Education major in English and Literature; BS Theology; AB Philosophy; and BS Secretarial Administration major in secretarial education. His research interests involve human resources, ethics and morality. 